\title{
hFOB 1.19 osteoblast cells grown on a biomimetic biphasic nanoscaffold: an in vitro evaluation for possible bone tissue engineering.
}

\author{
Ilse du Preez ${ }^{1,2 *}$, Wim Richter ${ }^{1}$, Dirk van Papendorp ${ }^{2}$, Annie Joubert ${ }^{2}$ \\ ${ }^{1}$ Council for Scientific and Industrial Research, Polymers and Composites, Material Science and Manufacturing, \\ Pretoria, South Africa \\ ${ }^{2}$ Department of Physiology, School of Medicine, Faculty of Health Sciences, University of Pretoria, Pretoria, South \\ Africa
}

\begin{abstract}
Much research over the past five decades has focussed on the repair and replacement of bone. Recently, the research focus has shifted to nanotechnology since it provides a platform from which to alter and possibly improve materials' properties. In this study we have made use of previously developed electrospun biphasic nanoscaffolds to culture osteoblast cells on, and investigate specific responses of the cells towards the scaffolds. Osteoclast-like cells and osteoblast cells were cultured separately on the nanoscaffolds and the proliferation, adhesion and cellular response were determined. In this study, the mineralisation of the osteoblast cells was observed in a time study. The intracellular calcium ion concentration and nitric oxide concentration were determined in vitro while the cells were proliferating on the scaffolds. The expression of endothelial and inducible nitric oxide synthase was determined immunohistochemically. Quantitative data were obtained from fluorometer studies. Qualitative data was supplied by light- and fluorescent confocal microscopy. During studies with microscopy, a minimum of five representative images from each sample were captured. The cells showed increased mineralisation over time. An increase in intracellular $\mathrm{Ca}^{2+}$ was not observed when compared to the controls. However, an increase in intracellular nitric oxide formation was detected. Expression of endothelial nitric oxide synthase but not inducible nitric oxide synthase was detected in vitro. From the results we can conclude that the scaffolds are biocompatible and conducive to healthy cell growth and differentiation and could possibly be applied in non-load-bearing bone regeneration and repair applications.
\end{abstract}

Keywords: Osteoblast, hFOB 1.19, Bone tissue engineering, Mineralisation, Endothelial nitric oxide, Inducible nitric oxide. Abbreviations: ${ }^{\circ} \mathrm{C}$ : Degrees Celsius; $\mu \mathrm{m}$ : Micrometer; ANOVA: Analysis of Variance; ARS : Alizarin Red-S; ATR-FTIR: Attentuated Total Reflectance Fourier Transform Infrared; $\mathrm{Ca}^{2+}$ : Calcium Ion; CSIR: Council for Scientific and Industrial Research; DAF-2 DA: 4,5-Diaminoflurescein Diacetate; DAPI: Blue Fluorescent 4',6-Diamidino-2Phenylindole; DCM: Dichloromethane; EDTA: Ethylene diaminetetraacetic Acid; eNOS: Endothelial Nitric Oxide Synthase; FCS: Fetal Calf Serum; FITC: Fluorochrome Fluorescein Isothiocyanate; HA: Hydroxyapatite; HAM: Nutrient Mixture F-12; hFOB 1.19: Human Fetal Osteoblast Cell Line; kV: Kilovolts; LDH: Lactate Dehydrogenase; PBS: Phosphate Buffer Saline; pen/strep: penicillin/streptomycin; RFU: Relative Fluorescence Units; RPM: Revolutions Per Minute; RT: Room Temperature; SD: Standard Deviation; SEM: Scanning Electron Microscopy; Ti: Titanium; v/v: volume/volume; XRD: X-Ray Diffraction; $\beta$ - TCP: $\beta$-Tricalcium Phosphate.

Accepted on April 11, 2018

\section{Introduction}

Bone is dynamic living tissue consisting of macro-, micro- and nanostructures. Bone consists of nanocrystals of hydroxyapatite that are dispersed in a matrix of collagen I $[1,2]$. Since the early 1960 's, research on bone replacement and repair focussed more on bioinert materials that are strong, such as titanium or stainless steel. Current research is directed at biocompatible and biomimetic materials to replace bone, which would be able to assist in the healing process [3-7] and start to dissolve when they are implanted in the body and are being replaced by the patient's own tissue [8-11].

Calcium phosphate-based materials are the most widely used in creating synthetic bioactive bone substitutes for implantations. Unfortunately, one of the drawbacks of using such materials (e.g. Hydroxyapatite (HA) and $\beta$-Tricalcium Phosphate ( $\beta$ TCP)) is their brittleness, which results from a lack of collagen fibres [4,12-16]. Ideally, a perfectly designed scaffold would guide and assist in tissue formation when implanted into the 
affected site. The material should be three-dimensional with pore sizes around $260 \mu \mathrm{m}$ to promote successful ingrowth of the surrounding tissue. The scaffold should assist in (a) the recruitment process of a patient's own cells to the implant site and in the process be resorbed by the osteoclasts over time, whilst (b) the osteoblasts deposit newly mineralised bone [15,17-21].

Current orthopaedic devices on the market include nails, plates, screws and joint replacements, dental cranio-maxillofacial products manufactured from Titanium (Ti) plates and carbon composite materials used to produce artificial legs $[5,16,22,23]$. All these products are metal and thus lack the necessary porosity that would aid in vascularisation and subsequent in-growth of tissue. The use of HA-based scaffolds is very promising since it is proven to be both osteoconducting and osteo-inducting, promoting osteoblastic cell adhesion, growth and differentiation of and the formation of new bone [24-29].

We have shown the successful manufacturing of biphasic electrospun scaffolds that showed promising results in vitro [30]. Previously, the proliferation, adhesion and cellular response of the osteoblast cells were determined using (a) Lactate Dehydrogenase (LDH) cytotoxicity assay, (b) nucleus and cytoskeleton dynamics, (c) analysis of the cell cycle progression, (d) measurement of the mitochondrial membrane potential and (e) the detection of phosphatidylserine expression [30]. These electrospun biphasic (HA/ $\beta-\mathrm{TCP})$ nanobioceramic scaffolds were utilised in this study to monitor hFOB 1.19 osteoblast cells' response to these scaffolds. We particularly focussed on the mineralisation of the osteoblast cells after a number of days growing on the electrospun scaffolds [31,32], as well as the production of Nitric Oxide (NO), since it is a signal of possible early increased formation of bone [33]. Our group also investigated the expression of endothelial nitric oxide (eNOS) and inducible nitric oxide (iNOS) with specific antibodies and visualised it with confocal microscopy [34]. The determination of the intracellular calcium concentration of the osteoblast cells was also included in this study, since an increase in the intracellular calcium concentration may lead to a decrease in cell proliferation [35].

\section{Materials and Methods}

\section{Fabrication of nano-biphasic scaffolds}

The manufacturing and characterisation of the biphasic bioceramic electrospun scaffolds as previously reported by our group [30]. The manufacturing of the electrospun scaffolds was done by using a $40 \%$ HA to $60 \% \beta$-TCP ratio in a $30 \% \mathrm{v} / \mathrm{v}$ final total. Acetone (50\%) and acetic acid (50\%) was used as the solvents and gelatine was added drop wise to the mixture to reach $5 \%-7 \%$ of the total volume while stirring. Upon the application of a high voltage $(15 \mathrm{kV})$ it was possible to draw the biphasic suspension into fibres. These biphasic bioceramic electrospun scaffolds were then used for cell culture studies [30]. The scaffolds were characterised by Scanning Electron Microscopy (SEM), X-Ray Diffraction (XRD) and Attenuated
Total Reflectance Fourier Transform Infrared (ATR-FTIR) [30].

\section{hFOB 1.19 cell culture}

The human osteoblastic cell line hFOB 1.19 (American Type Culture Collection (ATCC), Arlington, Virginia, USA, CRL-11372) was cultured in Dulbecco's Modified Eagle's Medium (DMEM) and Nutrient mixture F-12 (HAM) (F-12 media) (1:1), supplemented with $10 \%(\mathrm{v} / \mathrm{v})$ heat-inactivated Fetal Calf Serum (FCS) and 1\% (v/v) penicillin/streptavidin (pen/strep) (Gibco, Life Technologies, Johannesburg, South Africa) at $37^{\circ} \mathrm{C}$ in an atmosphere of $5 \% \mathrm{CO}_{2}$. Cells were grown in $25 \mathrm{~cm}^{2}$ culture flasks as an adhesion culture and after $3 \mathrm{~d}$ transferred to $75 \mathrm{~cm}^{2}$ culture flasks where they were cultured to reach confluence. Sterilisation of the electrospun scaffolds was done by immersion in ethanol for $20 \mathrm{~min}$ prior to cell seeding. Cells were seeded at a density of 150,000 cells/ well on the biphasic bioceramic electrospun scaffolds and the adherent cells were cultured up to $6 \mathrm{~d}$ with changing of media every two days. Detachment of adherent cells was achieved by adding $\quad 0.05 \%$ trypsin containing $0.1 \%$ Ethylenediaminetetraacetic Acid (EDTA) and cells were counted by trypan blue assay using a haemocytometer.

\section{Mineralisation of the hFOB 1.19 osteoblast cell line}

The hFOB 1.19 cells growing on the electrospun biphasic scaffolds were washed with 1X Phosphate Buffer Saline (PBS) buffer three times and fixed in ice cold $70 \%$ ethanol for $1 \mathrm{~h}$. After fixation, the scaffolds with fixed cells were washed three times with $\mathrm{dH}_{2} \mathrm{O}$ and stained with Alizarin Red-S (ARS) (Sigma-Aldrich SA (Pty) Ltd. (Johannesburg, South Africa)) (40mM, pH 4.1) for $20 \mathrm{~min}$ at room temperature. The cells on the scaffolds were washed several times after incubation with $\mathrm{dH}_{2} \mathrm{O}$ several times and observed under the phase contrast optical microscope (Carl Zeiss, Primo Vert microscope, Germany) [36].

\section{Intracellular nitric oxide determination in hFOB 1.19 osteoblast cells}

The fluorescent probe 4,5-Diaminofluorescein Diacetate (DAF-2 DA) was used to detect intracellular NO content of cells, according to manufacturer's instructions. After detachment of cells, the cell suspension was centrifuged at $125 \mathrm{X} \mathrm{g}$ for $10 \mathrm{~min}$. 100,000 cells/well (96-well, black plate) were cultured for $2 \mathrm{~h}$ at $37^{\circ} \mathrm{C}, 5 \% \mathrm{CO}_{2}$. After culturing, $200 \mu \mathrm{l}$ of the appropriate reaction mixture was added to the wells, as per manufacturer's instructions (nitric oxide detection system (fluorimetric), Sigma-Aldrich, Johannesburg, South Africa). After $2 \mathrm{~h}$ incubation, the fluorescence was measured. Excitation of DAF-2 DA was at $490 \mathrm{~nm}$ and the emitted fluorescence wavelength was $520 \mathrm{~nm}$. A fluorescent plate reader (Bio-Tek Instruments, FLx800) was used to read the fluorescence [34]. The controls for this assay included: (1) a control with non-induced cells serving as a negative control; (2) the complete reaction mixture minus any osteoblast cells to determine baseline fluorescence; and (3) osteoblast cells grown 
on tissue-culture plastic with the addition of the complete reaction mixture without the dye to determine background fluorescence.

\section{Intracellular calcium ion concentration determination in hFOB 1.19 osteoblast cells}

The Fluo-4 NW calcium assay kit (Invitrogen, Oregon, USA, supplied by Life Technologies, Johannesburg, South Africa) was used to measure intracellular $\mathrm{Ca}^{2+}$ concentration according to manufacturer's instructions. Osteoblast cells $(125,000$ cells/ well, 96-well black plate) were cultured in the presence of the biphasic bioceramic electrospun scaffolds for a period of $6 \mathrm{~d}$. Following the manufacturer's instructions, a stock solution $(250 \mathrm{mM})$ of probenecid acid was prepared. Probenecid acid stock solution $(100 \mu \mathrm{l})$ was added to $5 \mathrm{ml}$ of assay buffer (supplied in kit) to make a $2 \mathrm{X}$ dye solution. The $2 \mathrm{X}$ dye solution $(50 \mu \mathrm{l})$ was added to each well, incubating the plate at $37^{\circ} \mathrm{C}$ for $30 \mathrm{~min}$ followed by incubation at room temperature for another $30 \mathrm{~min}$. Excitation of the dye was achieved at 494 $\mathrm{nm}$ and the emission of fluorescence was measured at $516 \mathrm{~nm}$ with a fluorescent plate reader (Bio-Tek Instruments, FLx800) [37]

\section{Endothelial nitric oxide synthase and inducible nitric oxide synthase determination}

Cells were fixed with paraformaldehyde in PBS (2\%) for 10 min at $4^{\circ} \mathrm{C}$ where after samples were permeabilized with methanol for $10 \mathrm{~min}$ at $-20^{\circ} \mathrm{C}$ and washed (1\% BSA in PBS). Osteoblast cells on the scaffolds were incubated at $4^{\circ} \mathrm{C}$ for $1 \mathrm{~h}$ with either the primary antibody anti-eNOS (1:100) or the primary antibody anti-iNOS (1:100) (Invitrogen (Pty) LTD, supplied by Life Technologies, Johannesburg, South Africa). Goat $\alpha$-rabbit (1:100) labelled with Fluorescein Isothiocyanate (FITC) (Rockland, Hamburg, Germany) was used as the secondary antibody. Cell nuclei were stained with 4',6diamidino-2-phenylindole (DAPI) (Invitrogen (Pty) LTD, supplied by Life Technologies, Johannesburg, South Africa) (3 $\mu \mathrm{M}$ in PBS) for confocal microscopy. The slides were preserved with FluoroGuardTM reagent and examined with a confocal microscope (Olympus BX41, CC12 soft imaging system, Hamburg, Germany) at the electron microscope unit of the University of Pretoria (Pretoria, South Africa). FITC fluorescence was excited at $488 \mathrm{~nm}$ and emmitance was measured at 530/30 nm. DAPI's fluorescence was excited at $405 \mathrm{~nm}$ and measured at 420-480 $\mathrm{nm}$ [34].

\section{Statistical analysis}

Quantitative data were obtained from fluorometer studies (intracellular NO detection and intracellular $\mathrm{Ca}^{2+}$ determination). Data from three independent experiments $(n=5)$ are shown as the mean \pm Standard Deviation (SD) and was statistically analysed for significance using the analysis of variance ANOVA-single factor model followed by a two-tailed student's t-test. Means are presented with bar charts, with Tbars referring to standard deviations. P-values of less than 0.05 were regarded as statistically significant and are indicated by an asterisk $(*)$.

Qualitative data was supplied by light microscopy (ARS staining) and fluorescent confocal microscopy (Olympus BX41, CC12 soft imaging system, Hamburg, Germany). During studies with microscopy, a minimum of at least five representative images from each sample were captured.

\section{Results}

\section{Characterisation of biomimetic biphasic electrospun scaffolds}

Briefly, as published previously by our group [30], ATR-FTIR analysis of the biphasic electrospun scaffold showed the characteristic $\mathrm{OH}$ stretching for $\mathrm{HA}$ at $3570 \mathrm{~cm}^{-1}$, as detected in the pure HA sample as well. Peaks are observed at 1416.2 $\mathrm{cm}^{-1}$ and $1486 \mathrm{~cm}^{-1}$. These peaks can possibly be attributed to the carbonate ion $\mathrm{CO}_{3}{ }^{2-}$, which is an impurity present in both pure HA as well as the experimental sample (data published previously, [30]). SEM images of biphasic electrospun scaffolds showed beadless and porous nano fibers that were formed under controlled conditions. The HA/ $\beta$-TCP with gelatine electrospun scaffolds showed uniform nano fibers and interconnected pores with fiber sizes in the $100 \pm 10 \mathrm{~nm}$ range. Scaffolds with 5, 7 and $10 \%$ gelatine exhibited better uniformity of nano fibers. It was decided to use the scaffolds with $10 \%$ gelatine in this study, since these scaffolds presented the best uniformity of fibers with no beads on string formations (data published previously) [30].

\section{Alizarin Red-S staining of hFOB 1.19 osteoblast cells}

ARS binds selectively to calcium salts and is widely used for calcium mineral histochemistry. ARS was used to detect mineralization of the osteoblast cells after 0,3 and $6 \mathrm{~d}$ of growth $[15,36,38]$. On $d 0$, the red staining of calcium salts was almost non-existent. By day 3 an increase in the intensity of red staining could be observed while day 6 showed an even further increase in red staining and thus mineralisation of hFOB 1.19 osteoblasts (Figure 1).

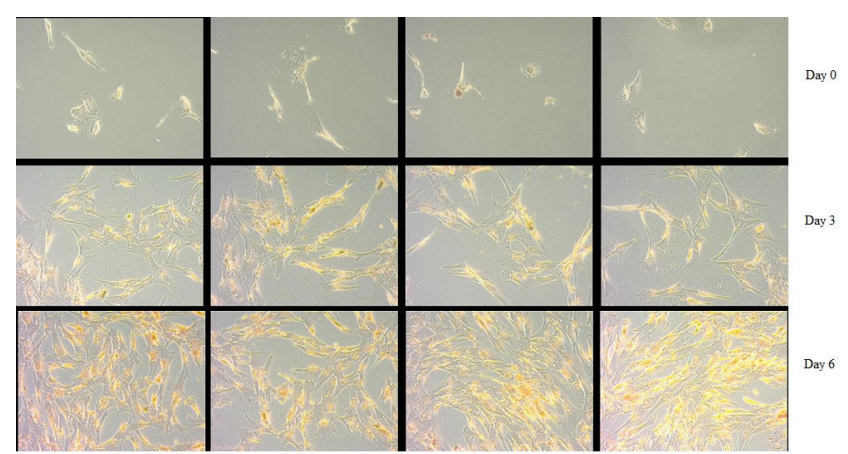

Figure 1. ARS staining of hFOB 1.19 osteoblast cells grew on biphasic electrospun scaffolds after 0, 3 and $6 d$. Staining was done to observe the mineralization of the hFOB 1.19 osteoblast cells. An increase in red hue intensity was noticed as time lapsed which indicated the mineralization of the osteoblast cells. 


\section{Intracellular nitric oxide determination of hFOB 1.19 osteoblast cells}

Nitric oxide plays a role in different cellular processes in control of bone turnover. NO is generated by the endothelial nitric oxide synthase (eNOS) that is constitutively expressed in osteoblasts. The eNOS's role in osteoblasts is to aid in proliferation and differentiation of the cells. Therefore, the detection of NO is considered an early indicator of increased formation of bone. In osteoclasts, decreased levels of NO are responsible for an increase in osteoclastogenesis and bone resorption. Higher NO levels in osteoclasts inhibit the bone resorption process by the inhibition of cytokines that are associated with osteoclastogenesis [39] (Figure 2).

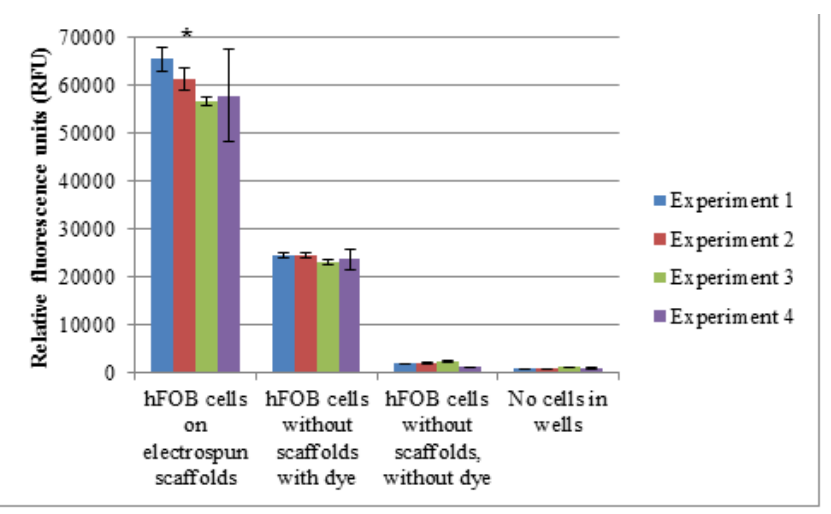

Figure 2. Graphical representation of intracellular NO determination in hFOB 1.19 osteoblast cells grown on biphasic electrospun scaffolds and cultured on tissue-culture plastic (control). Two additional controls was also included as per manufacturer's instructions, namely hFOB 1.19 osteoblast cells grown on tissueculture plastic without assay dye (to determine background fluorescence), as well as complete assay reaction mixture without cells. The graph is representative of four independent repeats of the assay, each with an n-value of 3. Standard deviation was indicated by the T-bars. ("indicates a statistically significant difference when compared to the osteoclast-like cells grown on tissue-culture plastic as control, with a $p$ value of <0.05). A significant difference in fluorescence intensity was observed between the osteoblast cells grown on the biphasic electrospun scaffolds and cells grown on tissue-culture plastic as a control. This is indicative of an increase in intracellular NO concentration which in turn indicates early stages of bone formation.

\section{Intracellular calcium concentration determination of hFOB 1.19 osteoblast cells}

When foreign materials such as the biphasic electrospun scaffolds are presented to the in vitro environment of cells, it is possible for the intracellular calcium ions to be increased. An increase in the intracellular calcium ion concentration of the cells could lead to a decrease in cell proliferation, which leads to lower cell numbers [37].

hFOB 1.19 cells were grown on the scaffolds, as well as a control of cells grown without scaffolds (on tissue-culture plastic). An additional control was included-the entire reaction mixture without any cells present (Figure 3) [37].

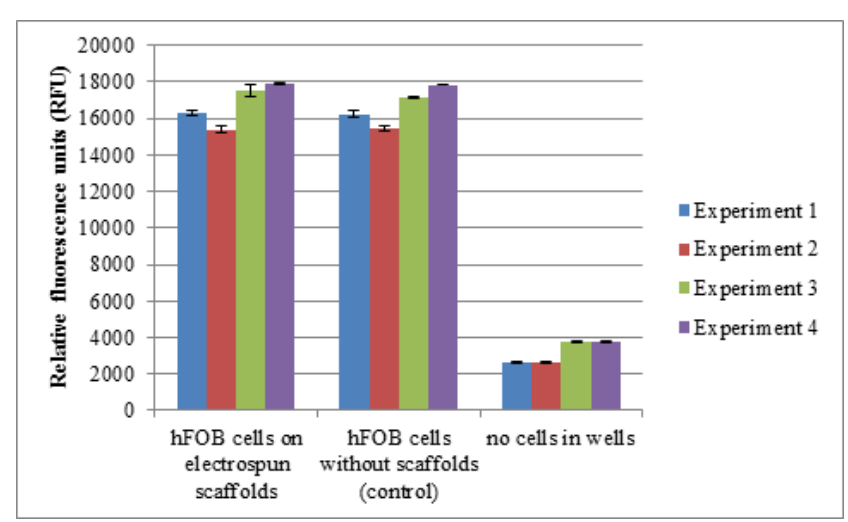

Figure 3. Graphical representation of intracellular $\mathrm{Ca}^{2+}$ determination in hFOB 1.19 osteoblast cells grown on biphasic electrospun scaffolds and grown on tissue-culture plastic (control). One additional control was also included as per manufacturer's instructions, namely an assay cocktail without cells. The graph represents four independent repeats of the assay, each with an $n$ value of 3. Standard deviation is indicated by the T-bars; * indicates a statistically significant difference when compared to the osteoclastlike cells grown on tissue-culture plastic as control, with a $p$ value of $<0.05$. There was a significant difference between the data collected from the assay cocktail mix with no cells present and the other two samples. No significant difference between the hFOB 1.19 osteoblast cells grown on the biphasic electrospun scaffold and those cells grown on tissue-culture plastic (control), were detected, indicating that no significant increase in intracellular $\mathrm{Ca}^{2+}$ ions was detected.
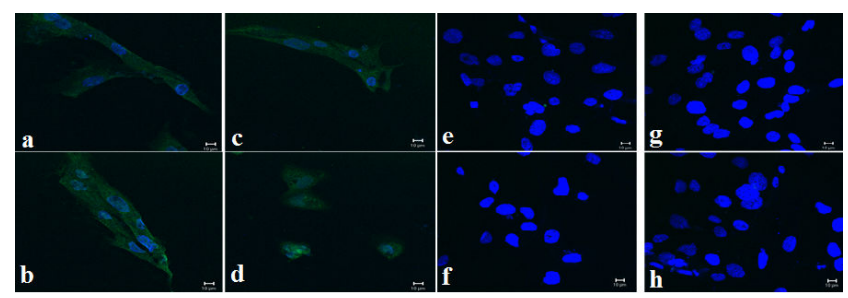

Figure 4. Expression of endothelial nitric oxide synthase (eNOS) in hFOB 1.19 osteoblasts cultured on glass cover slips as control (a and b) and on $H A / \beta-T C P / g e l a t i n e ~ e l e c t r o s p u n$ scaffolds ( $c$ and $d$ ) analysed by confocal microscopy after immunostaining with a primary polyclonal antibody anti-eNOS and a secondary antibody labelled with fluorescein (FITC, in green). Expression of inducible nitric oxide synthase (iNOS) in hFOB 1.19 osteoblasts cultured on glass cover slips (control) ( $e$ and $f$ ) and on $H A / \beta-T C P / g e l a t i n e$ electrospun scaffolds ( $g$ and $h$ ) analysed by confocal microscopy after immunostaining with a primary polyclonal antibody anti-iNOS and a secondary antibody labelled with fluorescein (FITC, in green). Cell nuclei were stained with DAPI (in blue).

\section{Endothelial and inducible nitric oxide synthase detection in hFOB 1.19 osteoblast cells}

Osteoblast cells are constitutively expressing the enzyme endothelial nitric oxide synthase. The enzyme plays a key role in osteoblast activity regulation and the formation of bone as a result of its involvement in the differentiation and function of osteoblasts $[34,40]$. The expression of eNOS was analysed in the hFOB 1.19 cells cultured on the biphasic electrospun scaffolds by confocal microscopy making use of the antibody anti-eNOS. The subcellular localisation of eNOS (indicated in 
green in Figure 4) can be seen in both the control cells (cells grown on tissue culture plastic) as well as the osteoblasts grown on the biphasic electrospun scaffold. The nuclei of the osteoblast cells were stained with DAPI (indicated in blue) (Figure 4).

\section{Discussion}

In Figure 1, the ARS staining of the hFOB 1.19 osteoblast cells growing on the electrospun biphasic scaffold showed that mineralization does take place. On d 0 , no red stain was seen in the cells. However, as the cells differentiated into more mature osteoblasts, the red was visible at d 3 and increased in colour intensity by $\mathrm{d} 6$, staining positive for mineralization. The ARS did bind successfully to the calcium salts present in the osteoblast cells.

Figure 2 represents the intracellular NO determination in hFOB 1.19 osteoblast cells grown on biphasic electrospun scaffolds and cultured on tissue-culture plastic (control). Two additional controls were also included as per manufacturer's instructions, namely hFOB 1.19 osteoblast cells grown on tissue-culture plastic without assay dye (to determine background fluorescence), as well as complete assay reaction mixture without cells. The graph is representative of four independent repeats of the assay, each with an n-value of 3. Standard deviation was indicated by the T-bars. A significant difference in fluorescence intensity was observed between the osteoblast cells grown on the biphasic electrospun scaffolds and cells grown on tissue-culture plastic as a control. This is indicative of an increase in intracellular NO concentration which in turn indicates early stages of bone formation.

When a scaffold such as the biphasic electrospun scaffold is introduced into the cell environment, one can expect some dissolution of the scaffold. The dissolution of the scaffold could lead to an increase in the availability of $\mathrm{Ca}^{2+}$ ions in the media. An increase in the intracellular $\mathrm{Ca}^{2+}$ ions in the cells could lead to slower proliferation of the cells, which might have an influence on the cell numbers. From the results as presented in Figure 3, no significant difference in the fluorescent intensity of the probe was detected in the osteoblast cells grown on the electrospun scaffolds when compared to the cells grown on the tissue-culture plastic as a control. This is indicative of no increase in the intracellular $\mathrm{Ca}^{2+}$ ion content of the cells, which might lead to a decrease in cell numbers. There was, however, a significant difference between the cells that were grown on the electrospun scaffolds and "no cells in well" control, as well as the cells grown on the tissue-culture plastic as control and the "no cells in well" control. This shows that the assay was performed correctly and that the probe selectively bound to the intracellular $\mathrm{Ca}^{2+}$ ions.

In contrast to the eNOS's expression, iNOS is only expressed in response to external inflammatory stimuli. iNOS expression was analysed in hFOB 1.19 osteoblasts cultured on the biphasic electrospun scaffolds using a specific anti-iNOS antibody and visualising with confocal microscopy. Results indicated that the amount of iNOS that is expressed in both the control cells and the osteoblast cells grown on the electrospun scaffold are not detectable, indicating the absence of proinflammatory stimuli [34,41]. The biocompatibility of the biphasic electrospun scaffolds is highlighted by the absence of the expression of the iNOS since the iNOS pathway's activation is dependent on pro-inflammatory cytokines and/or endotoxins (Figure 4).

\section{Conclusion}

Previous work published by our group [30] has shown that the electrospun biphasic scaffolds are appropriate for growth, differentiation and mineralisation of osteoclast-like- and osteoblast cells for bone-tissue engineering. In this study, we have furthered our investigation into the influence that the electrospun biphasic scaffolds has on, specifically, the hFOB 1.19 osteoblast cells. This study focussed on the mineralisation of the cells, the intracellular $\mathrm{Ca}^{2+}$ and NO concentration as well as the expression of eNOS and iNOS by the cells. The cells showed increased mineralisation with an increase in time, with $\mathrm{d} 6$ having a more intense red hue when compared to $\mathrm{d} 0$ cells. While the cells were growing on the electrospun biphasic scaffolds, an increase in intracellular $\mathrm{Ca}^{2+}$ was not observed when compared to the controls. However, an increase in intracellular NO formation was detected. These results indicate that possible early formation of bone is occurring on the scaffolds. Expression of eNOS but not iNOS was detected in vitro, showing that the scaffolds are biocompatible and conducive to healthy cell growth and differentiation and could possibly be applied in non-load-bearing bone regeneration and repair applications.

\section{Declarations}

\section{Ethics approval and consent to participate}

This study did receive ethics approval. The protocol number was 220/2010 and it was approved by the University of Pretoria's Faculty of Health Sciences Research Ethics Committee.

\section{Consent for publication}

Not applicable

\section{Availability of data and material}

The datasets used and/or analysed during the current study are available from the corresponding author on reasonable request.

\section{Competing interests}

The authors declare that they have no competing interests.

\section{Funding}

This study was financially supported by the Council for Scientific and Industrial Research (CSIR), Pretoria, South Africa. Prof AM Joubert provided funds from a grant to obtain the hFOB 1.19 cells from the ATCC. 


\section{Authors' Contributions}

Ilse du Preez, Wim Richter \& Annie Joubert were involved in the initial design of the study. Ilse du Preez performed all the experimental work and analysed all the data. Ilse du Preez was also responsible for writing this manuscript. Wim Richter and Annie Joubert were supervisors and advised on the study and the results as well as assisted with co-authoring the manuscript. Dirk van Papendorp acted in an advisory and supervisor role. All authors read and approved the final manuscript.

\section{Acknowledgements}

Flow cytometric analysis was conducted at the Department of Pharmacology, Faculty of Health Sciences, University of Pretoria, Pretoria, South Africa. Spectrofluorometric readings were performed at Biosciences at the CSIR. Special thanks to the people working in Prof Joubert's laboratory, Department of Physiology, Faculty of Health Sciences, University of Pretoria, Pretoria, South Africa for support. Thanks go to Ms Barbara English of the Research Office in the University of Pretoria's Faculty of Health Sciences for editorial assistance.

\section{References}

1. Tomoaia G, Soritau O, Tomoaia-Cotisel M, Pop L, Pop A, Mocanu A, Horovitz O. Scaffolds made of nanostructured phosphates, collagen and chitosan for cell culture. Powder Technol 2013; 238: 99-107.

2. Cholas R, Kunjalukkal Padmanabhan S, Gervaso F, Udayan G, Monaco G, Sannino A, Licciulli A. Scaffolds for bone regeneration made of hydroxyapatite microspheres in a collagen matrix. Mater Sci Eng C Mater Biol Appl 2016; 63: 499-505.

3. Heinemann S, Heinemann C, Bernhardt R, Reinstorf A, Nies B, Meyer M, Worch H. Bioactive silica-collagen composite xerogels modified by calcium phosphate phases with adjustable mechanical properties for bone replacement. Acta Biomater 2009; 5: 1979-1990.

4. Schilling AF, Linhart W, Filke S, Gebauer M, Schinke T, Rueger JM, Amling M. Resorbability of bone substitute biomaterials by human osteoclasts. Biomaterials 2004; 25 : 3963-3972.

5. Holzapfel BM, Reichert JC, Schantz J, Gbureck U, Rackwitz L, Nöth U, Jakob F. How smart do biomaterials need to be? A translational science and clinical point of view. Adv Drug Deliv Rev 2013; 65: 581-603.

6. Sharifi E, Azami M, Kajbafzadeh A, Moztarzadeh F, Faridi-Majidi R, Shamousi A, Karimi R. Preparation of a biomimetic composite scaffold from gelatin/collagen and bioactive glass fibers for bone tissue engineering. Mater Sci Eng C Mater Biol Appl 2016; 59: 533-541.

7. Barbeck M, Booms P, Unger R, Hoffmann V, Sader R, Kirkpatrick CJ, Ghanaati S. Multinucleated giant cells in the implant bed of bone substitutes are foreign body giant cells-New insights into the material-mediated healing process. J Biomed Mater Res A 2017; 105: 1105-1111.
8. Heness G, Ben-Nissan B. Innovative bioceramics. Mater Forum 2004; 27: 104-114.

9. Armentano I, Dottori M, Fortunati E, Mattioli S, Kenny JM. Biodegradable polymer matrix nanocomposites for tissue engineering: A review. Polym Degrad Stab 2010; 95: 2126-2146.

10. Dorozhkin SV. Bioceramics of calcium orthophosphates. Biomaterials 2010; 31: 1465-1485.

11. Dziadek M, Stodolak-Zych E, Cholewa-Kowalska K. Biodegradable ceramic-polymer composites for biomedical applications: A review. Mater Sci Eng C Mater Biol Appl 2017; 71: 1175-1191.

12. Dorozhkin SV. Bioceramics based on calcium orthophosphates (Review). Glass Ceram 2007; 64: 442-447.

13. Chevalier J, Gremillard L. Ceramics for medical applications: A picture for the next 20 years. J Eur Ceram Soc 2009; 29: 1245-1255.

14. Sergey VD. Biphasic, triphasic and multiphasic calcium orthophosphates. Acta Biomater 2012; 8: 963-977.

15. Azami M, Ai J, Ebrahimi-Barough S, Farokhi M, Fard SE. In vitro evaluation of biomimetic nanocomposite scaffold using endometrial stem cell derived osteoblastlike cells. Tissue Cell 2013; 45: 328-337.

16. Laasri S, Taha M, Hajjaji A, Laghzizil A, Hlil EK. Mechanical properties of calcium phosphate biomaterials. Mol Cryst Liquid Cryst 2016; 628: 198-203.

17. Patterson J, Martino MM, Hubbell JA. Biomimetic materials in tissue engineering. Materials Today 2010; 13: 14-22.

18. Vallet-Regi M. Evolution of bioceramics within the field of biomaterials. C R Chim 2010; 13: 174-185.

19. Hench LL, Thompson I. Twenty-first century challenges for biomaterials. J R Soc Interface 2010; 7: 379-391.

20. Ciapetti G, Di Pompo G, Avnet S, Martini D, DiezEscudero A, Montufar EB, Ginebra M. Osteoclast differentiation from human blood precursors on biomimetic calcium-phosphate substrates. Biochimica et Biophysica Acta 2017; 50: 102-113.

21. Ritz U, Gotz H, Baranowski A, Heid F, Rommens PM, Hofmann A. Influence of different calcium phosphate ceramics on growth and differentiation of cells in osteoblast-endothelial co-cultures. J Biomed Mater Res B Appl Biomater 2016; 5: 1950-1962.

22. Bayram C, Demirbilek M, Yalçın E, Bozkurt M, Doğan M, Denkbaş EB. Osteoblast response on co-modified titanium surfaces via anodization and electrospinning. Appl Surf Sci 2014; 288: 143-148.

23. Bet-moushoul E, Mansourpanah Y, Farhadi K, Tabatabaei M. TiO2 nanocomposite based polymeric membranes: A review on performance improvement for various applications in chemical engineering processes. Chem Eng J 2016; 283: 29-46.

24. Albrektsson T, Johansson C. Osteoinduction, osteoconduction and osseointegration. Eur Spine J 2002; 10: $96-101$. 


\section{tissue engineering}

25. Habibovic P, Gbureck U, Doillon CJ, Bassett DC, van Blitterswijk CA, Barralet JE. Osteoconduction and osteoinduction of low-temperature 3D printed bioceramic implants. Biomaterials 2008; 29: 944-953.

26. Lee J, Kim Y. Hydroxyapatite nanofibers fabricated through electrospinning and sol-gel process. Ceram Int 2014; 40: 3361-3369.

27. Ramier J, Bouderlique T, Stoilova O, Manolova N, Rashkov I, Langlois V, Renard E. Biocomposite scaffolds based on electrospun poly(3-hydroxybutyrate) nanofibers and electrosprayed hydroxyapatite nanoparticles for bone tissue engineering applications. Mater Sci Eng C Mater Biol Appl 2014; 38: 161-169.

28. Chetty A, Wepener I, Marei MK, Kamary YE, Moussa RM. Synthesis, properties and applications of hydroxyapatite. Hydroxyapatite: Synthesis, Properties and Applications (1st Edn.). USA: Nova Publishers 2012; 91-132.

29. Li M, Zhang C, Cheng M, Gu Q, Zhao J. Small intestinal submucosa: A potential osteoconductive and osteoinductive biomaterial for bone tissue engineering. Mater Sci Eng C Mater Biol Appl 2017; 75: 149-156.

30. Wepener I, Richter W, van Papendorp D, Joubert AM. In vitro osteoclast-like and osteoblast cells response to electrospun calcium phosphate biphasic candidate scaffolds for bone tissue engineering. J Mater Sci Mater Med 2012; 23: 3029-3040.

31. Moester MJC, Schoeman MAE, Oudshoorn IB, van Beusekom MM, Mol IM, Kaijzel EL, Lowik CWGM. Validation of a simple and fast method to quantify in vitro mineralization with fluorescent probes used in molecular imaging of bone. Biochem Biophys Res Commun 2014; 443: 80-85.

32. Ibrahim S, Sabudin S, Sahid S, Marzuke MA, Hussin ZH, Kader Bashah NS, Jamuna-Thevi K. Bioactivity studies and adhesion of human osteoblast (hFOB) on siliconbiphasic calcium phosphate material. Saudi J Biol Sci 2016; 23: 56-63.

33. Leidi M, Dellera F, Mariotti M, Banfi G, Crapanzano C, Albisetti W, Maier JAM. Nitric oxide mediates low magnesium inhibition of osteoblast-like cell proliferation. J Nutr Biochem 2012; 23: 1224-1229.

34. Alcaide M, Serrano M, Pagani R, Sanchez-Salcedo S, Vallet-Regi M, Portoles M. Biocompatibility markers for the study of interactions between osteoblasts and composite biomaterials. Biomaterials 2009; 30: 45-51.
35. $\mathrm{Xu} J \mathrm{~J}$, Khor KA, Sui JJ, Chen WN. Preparation and characterization of a novel hydroxyapatite/carbon nanotubes composite and its interaction with osteoblastlike cells. Materials Sci Eng C 2009; 29: 44-49.

36. Venugopal J, Low S, Choon AT, Sampath Kumar TS, Ramakrishna S. Mineralization of osteoblasts with electrospun collagen/hydroxyapatite nanofibers. J Mater Sci Mater Med 2008; 19: 2039-2046.

37. $\mathrm{Xu}$ JL, Khor KA, Sui JJ, Zhang JH, Chen WN. Protein expression profiles in osteoblasts in response to differentially shaped hydroxyapatite nanoparticles. Biomaterials 2009; 30: 5385-5391.

38. Gregory CA, Grady Gunn W, Peister A, Prockop DJ. An Alizarin red-based assay of mineralization by adherent cells in culture: comparison with cetylpyridinium chloride extraction. Anal Biochem 2004; 329: 77-84.

39. Nichols SP, Storm WL, Koh A, Schoenfisch MH. Local delivery of nitric oxide: Targeted delivery of therapeutics to bone and connective tissues. Adv Drug Deliv Rev 2012; 64: 1177-1188.

40. Aguirre J, Buttery L, OShaughnessy M, Afzal F, Fernandez de Marticorena I, Hukkanen M. Endothelial nitric oxide synthase gene-deficient mice demonstrate marked retardation in postnatal bone formation reduced bone volume, defects in osteoblast maturation activity. Am J Pathol 2001; 158: 247-257.

41. Kenneth J, Armour KE, vant Hof RJ, Reid DM, Wei W, Liew FY. Activation of the inducible nitric synthase pathway contributes to inflammation-induced

42. osteoporosis by suppressing bone formation and causing osteoblast apoptosis. Arthritis Rheum 2001; 44: 2790-2796.

\section{*Correspondence to}

Ilse du Preez

Council for Scientific and Industrial Research

Polymers and Composites

Material Science and Manufacturing

South Africa

E-mail: idpreez@csir.co.za 